\section{CURSO DE BIBLIOTECONOMIA DA UNIVERSIDADE FEDERAL DE ALAGOAS: \\ Formando Competências e Transformando Realidades ${ }^{1}$}

A Ciência da Informação em Revista é, antes de tudo, a concretização de um sonho dos que fazemos o Curso de Biblioteconomia da Universidade Federal de Alagoas (UFAL). De pronto, podemos dizer que é resultado de esforços dos últimos 15 anos.

Tomando como referência esse intervalo de tempo, poderíamos abordar aqui conceitos, teorias, métodos, tecnologias, modelos, entre outros elementos que compõem a formação no Curso de Biblioteconomia. Esta, sem sombra de dúvida, é uma possibilidade, dentre tantas outras.

Nesta aura de nostalgia, vivência e celebração, queremos, contudo, sem perder de vista aquele horizonte, tomar outro caminho que nos condicione a apresentar com melhor clareza a trajetória que percorremos nestes anos. Essa escolha se deve ao fato de ela nos aproximar de uma abordagem mais teleológica expressa na insígnia que tem orientado nossa atuação: formar competências e transformar realidades.

Com efeito, mais do que retratar um estado de coisas, ela parece evidenciar um estado de espírito, que, diga-se de passagem, já se encontrava nas mentes daqueles que sonhamos, lutamos e conquistamos, notadamente das Bibliotecárias Silvia Regina Cardeal e Sueli Maria Goulart, que, em 1998, idealizaram, planejaram e implantaram o Curso de Biblioteconomia.

\footnotetext{
${ }^{1}$ Parte deste editorial compôs o discurso proferido pelo Coordenador do Curso de Biblioteconomia, Prof. Dr. Edivanio Duarte de Souza, na abertura do I Encontro Internacional de Ciência da Informação: múltiplos saberes, que foi realizado, na cidade de Maceió, em Alagoas, no dia 9 de maio de 2013, em comemoração aos 15 anos de implantação deste Curso.
}

Não nos resta dúvida de que a fase inicial foi bastante difícil, sobretudo, pela carência de infraestrutura e de professores. $\mathrm{O}$ Curso foi implantado no subsolo da Biblioteca Central e com corpo docente da área formado exclusivamente por professores substitutos.

Em 2005, ano de seu reconhecimento pelo Ministério da Educação (MEC), o Curso contava com apenas três professores efetivos: Clarice Vanderlei Ferraz, Edivanio Duarte de Souza e Virgínia Bárbara de Aguiar Alves. A situação não exige maior esforço para compreender que, até aquele momento, o nosso tempo foi dedicado integral e exclusivamente à sala de aula, à supervisão de estágios e à gestão administrativa e colegiada.

No ano de 2006, houve a ampliação do corpo docente com a contratação dos professores efetivos Francisca Rosaline Leite Mota e Marcos Aurélio Gomes.

Posteriormente, passaram a fazer parte do corpo docente, sequencialmente, os professores Maria de Lourdes Lima, Lívia Aparecida Ferreira Lenzi, Adriana Lourenço, Carlos Cândido de Almeida, Dalgiza Andrade Oliveira, Ronaldo Ferreira de Araújo, Iuri Rocio Franco Rizzi e Nelma Camêlo de Araújo $^{2}$. Essas contratações resultaram na ampliação das atividades com a implantação de projetos de extensão e de pesquisa.

Malgrado as dificuldades por que passamos, avançamos a passos consideráveis que nos autorizam a dizer que o Curso de Biblioteconomia já nasce à frente da ruptura com " [...] a representação artística do Bibliotecário tradicionalmente afundado em livros, com lupas apropriadas ao exame de textos paleográficos, sem nenhum apreço pelos usuários", para usar as palavras do ilustre Edson Nery da Fonseca ${ }^{3}$. De forma bastante simplificada, consideramos que o Curso foi

\footnotetext{
2 Nestes 15 anos, diversos professores substitutos colaboraram com o Curso de Biblioteconomia. Além disso, atualmente, os professores Carlos Cândido e Dalgiza Andrade de Oliveira não mais fazem parte do corpo docente.

${ }^{3}$ FONSECA, E. N. Introdução à Biblioteconomia. 2. ed. Brasília: Brinquet de Lemos/Livros, 2007. p. 95.
} 
implantado em uma fase de reorganização do campo da Biblioteconomia e Ciência da Informação, momento em que foram encerrados alguns cursos de pós-graduação stricto sensu em Biblioteconomia e abertos outros em Ciência da Informação, no Brasil.

Houve, nesse período, uma tentativa de transformar alguns cursos de Biblioteconomia em Curso de Gestão ou Ciência da Informação. É nesse diapasão que alguns pesquisadores entendem que, não obstante a ampliação do quantitativo dos cursos de graduação em Biblioteconomia, essa área passou por uma fase de arrefecimento.

Por outro lado, é também verdade que o Curso de Biblioteconomia foi implantado em uma fase de ebulição técnico-científica nacional e internacional caracterizada pela expansão da cultura informacional, que tem na sua base, conforme Yves-François Le Coadic ${ }^{4}$, a confluência de uma indústria, de uma tecnologia e de uma ciência da informação. $\mathrm{O}$ fato é que, se com a reestruturação do modo de produção capitalista e a emergência do modelo de desenvolvimento informacional (o informacionalismo), a informação passou a ser o elemento central dos meios de produção, conforme Manuel Castells ${ }^{5}$ e Armand Mattelart ${ }^{6}$, a Biblioteconomia, por se dedicar aos processos e produtos informacionais, ganha novos contornos nesse campo informacional.

A rigor, essas condições impõem a implantação de uma educação para informação, considerando as especificidades do contexto em que ela se desenvolve. Tratase, nas palavras de Le Coadic, de implantar e desenvolver uma formação cujo fundamento se encontra no informar-se e informar.

Acrescentemos a isso que o cenário educacional brasileiro em que se desenvolve inicialmente o Curso foi caracterizado por um movimento de flexibilização curricular promovida pela substituição do então denominado currículo minimo pelas novas

\footnotetext{
${ }^{4}$ LE COADIC, Y.-F. Ciência da Informação. 2.ed. Brasília: Brinquet de Lemos/Livros, 2004.

${ }^{5}$ CASTELLS, M. A Sociedade em rede. 4. ed. São

Paulo: Paz e Terra, 2000.

${ }^{6}$ MATTELART, A. História da sociedade da

informação. São Paulo: Edições Loyola, 2002.
}

diretrizes curriculares nacionais. Com efeito, essa dinâmica vem condicionando a organização de currículos voltados às realidades locais e regionais, sem perder de vista os cenários nacional e internacional.

O Projeto Pedagógico do Curso de Biblioteconomia procura atender às Diretrizes Curriculares Nacionais dos Cursos de Biblioteconomia (Parecer $n^{\circ}$ 492/2001 do Conselho Nacional de Educação), especificamente, no que se refere ao perfil dos formandos e às competências e habilidades, gerais e específicas.

Não podemos deixar de destacar que o esforço na ampliação do Curso vem sendo conjunto, com a participação de corpos discente e docente, também em torno da pesquisa. Os últimos anos foram marcados pela implantação de grupos de pesquisa registrados no Diretório de Grupos de Pesquisa no Brasil, mantido pelo Conselho Nacional de Desenvolvimento Científico e Tecnológico (CNPq). Nesses grupos, são realizadas pesquisas que aglutinam professores e alunos da Biblioteconomia e de outros cursos, principalmente, por intermédio do Programa Institucional de Bolsa de Iniciação Científica (PIBIC).

Da mesma forma, professores e alunos vêm se organizando em torno de projetos de extensão, que evidenciam o direcionamento ao aprimoramento e à maior qualidade da formação no Curso de Biblioteconomia.

Em termos mais precisos, merece sublinhar, por exemplo, que já no ano de 2004 os nossos alunos realizaram o $V$ Encontro Regional de Estudantes de Biblioteconomia, Documentação, Gestão e Ciência da Informação (EREBD); e, após quatro anos, o XXXI Encontro Nacional dos Estudantes de Biblioteconomia, Documentação, Gestão e Ciência da Informação (ENEBD).

Ademais, durante a realização do XXIV Congresso Brasileiro de Biblioteconomia, Documentação e Ciência da Informação (CBBD), em 2011, a discente Mona Cleide Quirino da Silva venceu o Prêmio Carminda Nogueira de Castro, com o melhor Trabalho de Conclusão de Curso (TCC). No ano de 2012, as discentes Rennata Maria Marques Batista e Rosanne Maria de Oliveira Silva venceram o Prêmio de 
Melhor TCC do Nordeste, promovido pela Associação Brasileira de Educação em Ciência da Informação (ABECIN). Nos últimos anos, nossos alunos vêm sendo reconhecidos com prêmios de excelência no Congresso Acadêmico da UFAL.

Além das atividades de ensino, pesquisa e extensão, o corpo docente vem obtendo reconhecimento no cenário nacional. A professora Francisca Rosaline Leite Mota teve sua tese premiada como a Melhor Tese da Universidade Federal de Minas Gerais (UFMG), concorrendo inclusive ao Prêmio de Melhor Tese promovido pela Associação Nacional de Pesquisa e Pós-Graduação em Ciência da Informação (ANCIB). É importante registrar o ingresso dos professores Marcos Aurélio Gomes e Ronaldo Ferreira de Araújo no doutorado da UFMG e da professora Clarice Vanderlei Ferraz no doutorado da Universidade do Porto.

Desse conjunto de atividades, resultam as participações em eventos técnico-científicos, tais como o Encontro Nacional de Pesquisa em Ciência da Informação (ENANCIB) e Congresso Brasileiro de Biblioteconomia, Documentação e Ciência da Informação (CBBD), e a produção científica.

Honra-nos também relatar que participamos ativamente da realização do XXIV CBBD, que teve sede na cidade de Maceió, e foi considerado um dos maiores eventos da área. Um sucesso que resultou na aquisição da sede da Associação Alagoana de Profissionais em Biblioteconomia (AAPB).

No ano passado, realizamos o I Encontro Internacional de Ciência da Informação: múltiplos saberes, em comemoração aos 15 anos do Curso de Biblioteconomia.

Recentemente, o corpo docente uniu esforços na elaboração de dois projetos: Projeto Pedagógico do Curso de Graduação em Biblioteconomia na Modalidade a Distância e o Curso de PósGraduação Lato Sensu em Gestão Estratégica de Recursos Informacionais, que serão oportunamente implantados.

No que se refere à estrutura física, a construção do prédio sede do Curso de Biblioteconomia foi concluída no início de 2014, com previsão para ocuparmos as novas instalações neste ano.
Não podemos deixar de mencionar e agradecer as parcerias já firmadas com diversos setores da UFAL, principalmente, com a Biblioteca Central, que, além de conceder o espaço em que funciona parte do Curso, tem nos atendido em duas importantes situações, a saber, a disponibilização de fontes e serviços de informação, e a oferta de espaços para a realização dos nossos estágios curriculares. Sem essa parceria, certamente, o Curso não seria o mesmo.

E, por fim, porém não menos importante, a parceria que vimos realizando com os órgãos de classe, o Conselho Federal de Biblioteconomia (CFB), o Conselho Regional de Biblioteconomia (CRB-4) e a AAPB. Queremos registrar, em particular, nossa satisfação e, por conseguinte, nossos agradecimentos aos eventos organizados, em conjunto, pelo Curso de Biblioteconomia, pelo Sistema de Biblioteca da UFAL e pela AAPB.

Temos consciência de que existe muito a sonhar, conquistar e realizar, com destaque para a qualificação de docentes com a realização de doutoramento, a ampliação da produção científica e a implantação de um Curso de Pós-Graduação Stricto Sensu.

Por isso, resta-nos renovar nossos compromissos junto à sociedade alagoana e, extensivamente, à brasileira. Em arremate, reconhecemos que os sonhos e o trabalho ainda existem, insistem e persistem para que possamos continuar no horizonte de novas conquistas!

Nesse contexto, lançamos a Ciência da Informação em Revista, que se propõe a ser um espaço aberto para produções originais, porém, sua conotação básica é a constante necessidade de revisão da produção do conhecimento, na medida em que este resulta de permanentes movimentos de recorrências e retificações do pensamento sobre os diversos objetos e problemas de estudo.

Este número inaugural é dedicado exclusivamente à publicação de trabalhos de autoria de professores e alunos do Curso, em pareceria com outros coautores, conforme podemos observar a seguir.

Edivanio Duarte de Souza Editor 